\title{
Medical specialty choice related factors in Mexican residents
}

\author{
Carlos Gutiérrez-Cirlos ${ }^{1}$, José de Jesús Naveja-Romero², Iwin Leenen³ and Melchor Sánchez-Mendiola ${ }^{4}$
}

${ }^{1}$ Instituto Nacional de Ciencias Médicas y Nutrición Salvador Zubirán, Medical Direction (Internal Medicine) and Faculty of Medicine, UNAM; ${ }^{2}$ PECEM, Faculty of Medicine, Universidad Nacional Autónoma de México (UNAM); ${ }^{3}$ Instituto Nacional para la Evaluación de la Educación;

${ }^{4}$ Coordinaciónde Desarrollo Educativo e Innovación Curricular (CODEIC), Coordinator, UNAM, Ciudad de México, Mexico

\begin{abstract}
Objective: This study explored choice factors in four specialties in Mexico. Methods: Mixed methods design. Qualitative phase: four focus groups with first-year residents, to obtain information of how specialty choice was done. With this information a web-based cross-sectional questionnaire was applied to residents registered in the 1st year of Postgraduate Studies Division, UNAM. Results: 32 residents participated in qualitative phase and for the quantitative phase, the survey was answered by 35 surgical, 28 gynecology, 61 internal medicine and 62 pediatric residents. The specialty choice decision was done during the last years of the medical career. The majority of the resident choice was a subspecialty after the general residency. The type of patient was more crucial to choose pediatrics while a good academic program was for internal medicine. Negative models and bullying were decisive to rule out surgery as well as a not well-known hospital was to rule out pediatrics. Conclusion: The specialty choice is done during undergraduate training, with the intention of doing a subspecialty. Demographic and personality traits were identified.
\end{abstract}

KEY WORDS: Specialty election. Residents. Mixed methods design. Qualitative. Quantitative.

\section{Introduction}

The choice of a specialty is determined by different factors, which have been studied with higher interest because graduate physicians choose primary care specialties (pediatrics, family medicine or internal medicine) less often, which has an impact on health systems and patient care. Bland et ai. ${ }^{1}$ proposed a model about the factors they influence on the selection of a specialty, which comprises five groups: the type of school where the student was trained, the student's characteristics (demographics, personality), the student's values (personal preferences), the needs to be met during the specialty (income, prestige, leisure time) and the way the students perceive the specialty. The design and methodology of this model are ideal for application to all specialties, with the corresponding adaptations per country and specialty. A model has been proposed for the choice of family medicine $^{2}$, where more weight is given to the decision process during the undergraduate medical studies.

In a new review carried out by Querido et al. ${ }^{3}$, this model is picked up with an emphasis on the type of medical school and differences between countries, since a classification of medical schools and the requirements for postgraduate education access per country are included ${ }^{4}$. In Mexico, the type of school is less determining for the decision owing to the particular characteristics of public or private education, unlike other countries, where funding is required to afford medical school, as in the USA. In the aforementioned review, Querido et al. ${ }^{3}$ criticize investigations on factors related to the selection of a specialty, and mention that:

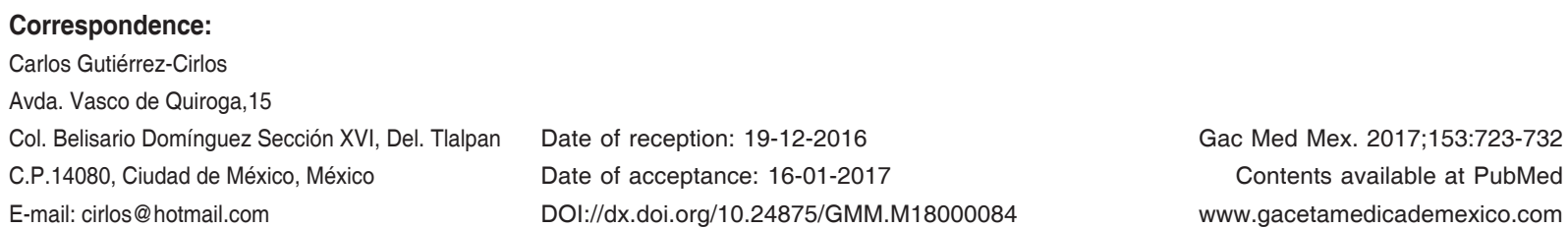

Col. Belisario Domínguez Sección XVI, Del. Tlalpan Date of reception: 19-12-2016 C.P.14080, Ciudad de México, México E-mail: cirlos@ hotmail.com

Date of acceptance: 16-01-2017

DOI://dx.doi.org/10.24875/GMM.M18000084

Gac Med Mex. 2017;153:723-732

Contents available at PubMed www.gacetamedicademexico.com 
- The process is not fully understood, since investigations are about one or several factors, but not on their possible interactions.

- More information is required on how the selection of a specialty can be determined by early exposure to different experiences (clinical, surgical or research).

- Most research is in students and on factors at the end of the undergraduate period. There is limited information assessing the factors that were related to the choice in residents.

- Studies are mostly quantitative (questionnaires). There is little qualitative or mixed research.

In Mexico, there is only few information about the factors that determine the choice in medical students or resident physicians. Since its implementation in 1976, the National Exam for Medical Residency Aspirants (ENARM - Examen Nacional para Aspirantes de Residencias Mèdicas), almost 26,000 physicians compete every year for around 6000 posts, with less than one out of every four physicians being selected to be trained for a specialty ${ }^{5-7}$. The result is decided according to the knowledge general average obtained. At the same time, the physician has to look for the hospital where he/she is to make the specialty, a process not necessarily coordinated with ENARM. In Mexico, as in most countries, available posts in hospitals depend on the supply and demand model, in addition to other population health estimators, the epidemiological profile and projections of posts' future demand, which are indicators that can be modified owing to the globalizing characteristics of the econo$\mathrm{my}^{7}$. In addition, Mexico has a low rate of specialists in comparison with other OECD countries. The rate is 1.2 per 1000 population, which is reduced to 0.8 in the public sector, owing to the lack of posts or to how unattractive they may be $\mathrm{e}^{7,8}$.

Personality has been described as a factor related to the choice of a specialty. The big five personality traits model ${ }^{9}$ has been applied to understand how a physician selects a particular specialty. Internal medicine specialists have been described as having a higher degree of awareness, as being more organized and persistent, but in general they are less extraverted, since they focus on the internal world rather than on social interaction. This is also explained by the fact that almost all of them tend to study a subspecialty. Obstetrics and gynecology specialists tend to be more extraverted and to have more sensitive thought and judgment; they are more conscious, organized, persistent and goal-oriented. They have lower scores with regard to openness to change and kindness and, in general, they are less sympathetic, trusting and cooperative. Pediatricians are more extraverted and sensitive, and have rational thought and critical judgment, which corresponds more to neuroticism, extraversion and kindness. Finally, surgeons have more capacity to adapt to change, and are extraverted and open. It is important pointing out that the above-mentioned personality differences are minimal among training specialists, and it is suggested that these differences further emerge once the specialists start practicing at the conclusion of residency ${ }^{10}$.

In this study, we investigated different factors that might have determined for a first year resident physician to have chosen one of the core specialties in Mexico: general surgery, obstetrics and gynecology, internal medicine or pediatrics.

\section{Method}

The study was carried out in first-year general surgery, obstetrics and gynecology, internal medicine and pediatrics resident physicians, enrolled in the Single Medical Specializations Plan (PUEM - Plan Único de Especializaciones Médicas) of the Postgraduate Division (DEP - División de Estudios de Posgrado) of the Faculty of Medicine of the National Autonomous University of Mexico (UNAM - Universidad Nacional Autónoma de México), based in Mexico City.

Of the educational research mixed methods, the one suggested for the development of a survey (sequential exploratory design) was used ${ }^{11,12}$. The method comprises a qualitative and a quantitative phase.

For the qualitative phase, 4 focal groups were developed, one for each specialty. A 13-question questionnaire was used (Appendix 1). Thirty-two residents from the following institutions participated: pediatrics at the Hospital Infantil de México Federico Gómez (HIMFG), obstetrics and gynecology at the Instituto Nacional de Perinatología Isidro Espinoza de los Reyes (INPER), and surgery and internal medicine at the Instituto Nacional de Ciencias Médicas y Nutrición Salvador Zubiurán (INCMNSZ). The focal groups formed at the above-mentioned institutions owing to accessibility, facilities and their rapid response for the focal groups to be developed. The contents of the testimonials, which were compared in terms of concepts and observations, were encoded. Subsequently, the information was organized according to conjunction with a pre-established category tree, and the emergent categories were identified during the 
interviews, in addition to narrations' emphasis and relevance.

In the quantitative phase, the information obtained from the focal groups and from questionnaires used in other publications was incorporaded ${ }^{13-16}$, and a questionnaire was designed that was applied online to the resident physicians. Evidence of content validity was obtained through a group of experts ${ }^{17}$ who assessed the clarity and relevance of each question. The questionnaire was divided in five sections and 157 questions: section I, factors to choose a specialty (21 questions); section II, factors to rule out a specialty (21 questions); section III, personality ipsative questionnaire (40 questions in adjective pairs); section IV, normative personality questionnaire (60 questions); and section $\mathrm{V}$, demographic factors (15 questions).

The two first sections enquired how present and how determinant was a factor to choose or discard a specialty. The answers were given in a Likert-type scale with 5 options: "nothing", "little", "moderately", "much" and "prefer not to answer". For the analysis, the variables were transformed into quantitative variables in a 0-to- 3 scale $(0=$ nothing; $3=$ much).

For the personality section, two previously developed questionnaires were employed. For the ipsative questionnaire (forced choice test) ${ }^{18,19}, 40$ pairs of adjectives that measure personality traits according to the 5 big traits model were used ${ }^{9,18}$ : extraversion, kindness, responsibility, emotional stability and openness. Of each pair of adjectives, the subject had to choose which described him/her best. For the normative questionnaire ${ }^{20,21}, 60$ statements were developed on how the person is (not on how he/she would like to be). Each 12-statement group (six in positive and six in negative sense) corresponded to one trait of the 5 major traits model. Section IV answers were given in a Likert-type scale with 5 options: " much in disagreement", "in agreement", "neither in agreement nor in disagreement", "in agreement" and "much in agreement". These answers were transformed into quantitative variable in a 0 -to- 4 scale $(0=$ much in disagreement; 4 = much in agreement), and with this, the means of the 12 questions for each trait were calculated.

The questionnaire was uploaded to the DEP Online Survey Platform with the LimeSurvey program (version 1.91+Build 11026). A pilot study with the online survey was run in 20 second-year internal medicine INCMNSZ resident physicians. Answering time was no longer than 20 minutes. The survey was sent to the e-mails of the 951 first-year resident physicians of the studied specialties enrolled in the UNAM Faculty of Medicine PUEM as of March 1, 2015. A reminder was sent before the resident physicians concluded the first year of residency in February 2016. The obtained information was analyzed with the IBM-SPSS Statistics 21 program for Windows. For the demographic variables, descriptive statistics were obtained, and for the variables deriving from the other sections, oneway analyses of variance (ANOVA) were carried out to detect significant differences $(p<0.05)$ between the four specialties. For the post hoc analysis, Tukey's test was used. The Wald test was used to assess whether there were differences in survey participation between the four specialties.

With regard to ethical aspects, the research work was approved by the Institutional Committee of the Master's Degree and Doctorate in Educational Research Postgraduate Program of the UNAM Faculty of Medicine. Informed consent was requested from the participants, participation was voluntary, and autonomy and confidentiality were respected. Reputation, performance, evaluations or job possibilities were not jeopardized, and the principles of the Declaration of Helsinki were observed.

\section{Results}

In the qualitative phase, the focus groups technique was used with the purpose to obtain information about attitudes, feelings, behaviors, beliefs and experiences related to the selection of a specialty. There were 32 participants, out of which 17 were females and 15 were males. The surgery ( 1 female and 5 males) and internal medicine groups ( 1 female and 7 males) were from the INCMNSZ, the obstetrics and gynecology group ( 7 females and 1 male) from the INPER and the pediatrics group (8 females and 2 males) from the HIMFG. Duration for each group was longer than 45 minutes. Qualitative information most relevant testimonials were: enrollment to the specialty was determined by the subspecialty they wanted to make; only for unforeseen issues (economic, family, health issues) would they drop out from the specialty; patient management, empathy and site of training; and the possibilities of exchange and to pursue master's degree or doctorate studies were also relevant to the decision. In table 1 , some of the most relevant testimonials are mentioned.

- Quantitative phase: The questionnaire was sent via e-mail to the 951 resident physicians enrolled in the PUEM, which is the largest medical 
Table 1. Focal group relevant categories and testimonial examples

\begin{tabular}{|c|c|}
\hline Focal group categories & Testimonial examples \\
\hline Influence of subspecialty on the election & $\begin{array}{l}\text { "Pediatrics is very diverse; you can devote to oncology, infectology or } \\
\text { gastroenterology. Personally, I find it a very broad specialty, more than other } \\
\text { specialties, because it focuses on medical and medical-surgical issues." (PR/F) }\end{array}$ \\
\hline Patient management and empathy & $\begin{array}{l}\text { "This is a specialty where we are in touch with pregnant women and we know it is a } \\
\text { moment of much vulnerability, they need understanding, empathy, but at the same } \\
\text { time, one has to be able to make decisions with a cool head, because many high- } \\
\text { risk situations emerge." (OGR/F) } \\
\text { "Among medicine many specialties, internal medicine is the one that has the most } \\
\text { complicated doctor-patient relationship, since most conditions are chronic. For } \\
\text { example: a surgeon operates a patient, and he gets rid of the problem; well, not } \\
\text { every time... Conversely, a diabetic patient will never stop being one, and having } \\
\text { a little closer relationship with the patient is needed in order to be able to have an } \\
\text { adequate. This interaction draws my attention (RIM/M) }\end{array}$ \\
\hline $\begin{array}{l}\text { Prestige and characteristics of the residency-training } \\
\text { hospital }\end{array}$ & $\begin{array}{l}\text { "... we are here because this was our first choice, because of what the institute } \\
\text { represents and the profile of the institute's graduate." (GSR/M) } \\
\text { "... the choice leans much more towards the place; I knew this was a highly } \\
\text { academic hospital, and for an internist it is essential having a highly academic } \\
\text { training." (IMR/M) }\end{array}$ \\
\hline Lifestyle & $\begin{array}{l}\text { "Following my patients' evolution motivates me, as well as learning more, but the } \\
\text { lifestyle we currently lead, the exhaustion discourage me." (OGR/F) } \\
\text { "I am the only woman here, I want to have children, and this specialty is where it } \\
\text { is more likely; I can't picture myself as a pregnant woman working in an operating } \\
\text { room or getting exposed to microorganisms or infections." (IMR/F) }\end{array}$ \\
\hline Probable causes for dropout & $\begin{array}{l}\text { "Just physical impairment." (GSR/M) } \\
\text { "Finding out that you don't like it and that this is not what you want to do on the long } \\
\text { term, and that it doesn't relate to the quality of life you want to have subsequently." } \\
\text { (OGR/F) }\end{array}$ \\
\hline
\end{tabular}

F: female gender; GSR: general surgery resident; IMR: internal medicine resident; M: male gender; OGR: obstetrics-gynecology resident; PR: pediatrics resident.

specialty program in the country. Thirty-three hospitals did participate: 18 secondary care and 15 tertiary care hospitals from 18 States of the Mexican Republic. There were 188 (20\%) complete answers obtained from the 951 resident physicians. Thirty-five (18\%) out of 198 surgeons, $28(15 \%)$ out of 184 obstetrician-gynecologists, $62(22 \%)$ out of 280 internists and $63(22 \%)$ out of 289 pediatricians did answer. A logistic regression was carried out, and the specialties were contrasted with Wald's test; there were no significant differences between groups with regard to participation in the survey $(p=0.08)$.

The distribution of the demographic characteristics of the 188 participants is presented in table 2. Average age was 28 years, most were of the female gender and single; almost all residents had no children and one third part had physician relatives.

The academic characteristics of the 188 surveyed subjects are presented in Table 3. More than half made their social service in a rural community, two out of every three took a preparation course for the ENARM and also two out of every three presented it for the first time. The decision to make a specialty was made by the end of the undergraduate studies: one out of every three during the internship, almost the same proportion during the social service. Seven out of every ten residents plan to finish the complete core specialty with a subspecialty.

With regard to the factors that influence on the selection or not of a specialty, assessment was made on how determinant was each one in the choice or dismissal of each one of the studied specialties. With regard to the decision to choose the specialty on which the surveyed subject most interested was at the moment of choice, the results were significant for the interest on the patient type and for choosing pediatrics and not surgery, in addition to a good academic program and choosing internal medicine rather than pediatrics. As for the decision to rule out one specialty, i.e., the one that least interesting was for the surveyed subject at the moment of choice, the results were significant for negative role models and constant abusive behaviors for not choosing surgery. A trend was observed towards low academic level of the place and little leisure time. The above results are resumed in figures 1 and 2, where the post hoc analysis (Tukey's 
Table 2. Distribution (absolute frequencies and percentages) of demographic characteristics of 188 surveyed resident physicians

\begin{tabular}{|c|c|c|c|c|c|c|}
\hline & \multicolumn{6}{|c|}{ Specialty } \\
\hline & GS & OG & IM & PED & Total & $p$ \\
\hline Surveyed population & $36(19 \%)$ & $28(15 \%)$ & $61(32 \%)$ & $63(34 \%)$ & 188 & \\
\hline Age in years (average) & 28.1 & 30.4 & 28 & 27.7 & 28.3 & $<0.001$ \\
\hline $\begin{array}{l}\text { Gender } \\
\text { Female } \\
\text { Male }\end{array}$ & $\begin{array}{l}11(31 \%) \\
25(69 \%)\end{array}$ & $\begin{array}{l}17(61 \%) \\
11(39 \%)\end{array}$ & $\begin{array}{l}33(54 \%) \\
28(46 \%)\end{array}$ & $\begin{array}{l}44(70 \%) \\
19(30 \%)\end{array}$ & $\begin{array}{c}105(56 \%) \\
83(44 \%)\end{array}$ & 0.002 \\
\hline $\begin{array}{l}\text { Marital status } \\
\text { Single } \\
\text { Non-single }\end{array}$ & $\begin{array}{c}31(86 \%) \\
5(14 \%)\end{array}$ & $\begin{array}{c}24(86 \%) \\
4(14 \%)\end{array}$ & $\begin{array}{c}55(90 \%) \\
6(10 \%)\end{array}$ & $\begin{array}{c}55(87 \%) \\
8(13 \%)\end{array}$ & $\begin{array}{c}165(88 \%) \\
23(12 \%)\end{array}$ & 0.38 \\
\hline $\begin{array}{l}\text { Has children } \\
\text { No } \\
\text { Yes }\end{array}$ & $\begin{array}{c}34(94 \%) \\
2(6 \%)\end{array}$ & $\begin{array}{c}25(89 \%) \\
3(11 \%)\end{array}$ & $\begin{array}{c}58(95 \%) \\
3(5 \%)\end{array}$ & $\begin{array}{c}59(94 \%) \\
4(6 \%)\end{array}$ & $\begin{array}{c}176(94 \%) \\
12(6 \%)\end{array}$ & 0.79 \\
\hline $\begin{array}{l}\text { Has physician relatives } \\
\text { No } \\
\text { Yes }\end{array}$ & $\begin{array}{l}26(72 \%) \\
10(28 \%)\end{array}$ & $\begin{array}{l}13(46 \%) \\
15(54 \%)\end{array}$ & $\begin{array}{l}42(69 \%) \\
19(31 \%)\end{array}$ & $\begin{array}{l}44(70 \%) \\
19(30 \%)\end{array}$ & $\begin{array}{l}125(66 \%) \\
63(34 \%)\end{array}$ & 0.11 \\
\hline
\end{tabular}

Values obtained with the ANOVA test for the age variable and chi-square with 10,000 simulations for the rest of variables.

GS: general surgery; IM: internal medicine; OG: obstetrics and gynecology; P: pediatrics.

Table 3. Distribution (absolute frequencies and percentages) of academic characteristics of 188 surveyed resident physicians

\begin{tabular}{|c|c|c|c|c|c|c|}
\hline & \multicolumn{6}{|c|}{ Specialty } \\
\hline & GS & OG & IM & PED & Total & $\mathrm{p}$ \\
\hline Surveyed population & $36(19 \%)$ & $28(15 \%)$ & $61(32 \%)$ & $63(34 \%)$ & 188 & \\
\hline \multicolumn{7}{|l|}{ Social service } \\
\hline Community & $17(47 \%)$ & $16(57 \%)$ & $33(54 \%)$ & $39(62 \%)$ & $105(56 \%)$ & 0.56 \\
\hline Teaching/research/other & $19(53 \%)$ & $12(43 \%)$ & $28(46 \%)$ & $24(38 \%)$ & $83(44 \%)$ & \\
\hline \multicolumn{7}{|l|}{ Undergraduate average } \\
\hline$<9$ & $23(64 \%)$ & $20(71 \%)$ & $30(49 \%)$ & $42(67 \%)$ & $115(61 \%)$ & 0.31 \\
\hline $9-10$ & $13(36 \%)$ & $8(29 \%)$ & $31(51 \%)$ & $21(33 \%)$ & $73(39 \%)$ & \\
\hline \multicolumn{7}{|l|}{ ENARM course } \\
\hline Yes & $24(67 \%)$ & $20(71 \%)$ & $37(61 \%)$ & $42(67 \%)$ & $123(65 \%)$ & 0.78 \\
\hline No & $12(33 \%)$ & $8(29 \%)$ & $24(38 \%)$ & $21(33 \%)$ & $65(35 \%)$ & \\
\hline \multicolumn{7}{|l|}{ Times ENARM was taken } \\
\hline 1 & $22(62 \%)$ & $12(43 \%)$ & $38(62 \%)$ & $48(76 \%)$ & $120(64 \%)$ & 0.03 \\
\hline 2 & $7(19 \%)$ & $13(46 \%)$ & $21(35 \%)$ & $12(19 \%)$ & $53(28 \%)$ & \\
\hline$>2$ & $7(19 \%)$ & $3(11 \%)$ & $2(3 \%)$ & $3(5 \%)$ & $15(8 \%)$ & \\
\hline \multicolumn{7}{|l|}{ Specialty selection } \\
\hline Prior to undergraduate studies & $2(5 \%)$ & $3(11 \%)$ & $4(6 \%)$ & $4(6 \%)$ & $13(7 \%)$ & 0.65 \\
\hline During undergraduate, prior to & $11(31 \%)$ & $9(32 \%)$ & $20(33 \%)$ & $15(24 \%)$ & $55(29 \%)$ & \\
\hline internship & $9(25 \%)$ & $10(36 \%)$ & $17(28 \%)$ & $16(25 \%)$ & $41(22 \%)$ & \\
\hline During internship & $6(17 \%)$ & $4(14 \%)$ & $11(18 \%)$ & $20(32 \%)$ & $41(22 \%)$ & \\
\hline During social service & $8(22 \%)$ & $2(7 \%)$ & $9(15 \%)$ & $8(13 \%)$ & $27(14 \%)$ & \\
\hline After social service & & & & & & \\
\hline \multicolumn{7}{|l|}{ Completed training } \\
\hline Complete core & $3(8 \%)$ & $8(29 \%)$ & $17(28 \%)$ & $8(13 \%)$ & $36(19 \%)$ & $<0.001$ \\
\hline Sub without core & $7(20 \%)$ & $0(0 \%)$ & $15(25 \%)$ & $4(6 \%)$ & $26(14 \%)$ & \\
\hline Sub with core & $26(72 \%)$ & $20(71 \%)$ & $29(47 \%)$ & $51(81 \%)$ & $126(67 \%)$ & \\
\hline
\end{tabular}

Values obtained with the chi-square test with 10,000 simulations for the rest of variables.

GS: general surgery; IM: internal medicine; OG: obstetrics and gynecology; P: pediatrics.

test) to identify significant differences between specialties is also shown.
The reliability of the personality normative questionnaire (Cronbach's $\alpha$ ) was 0.59 for kindness and 


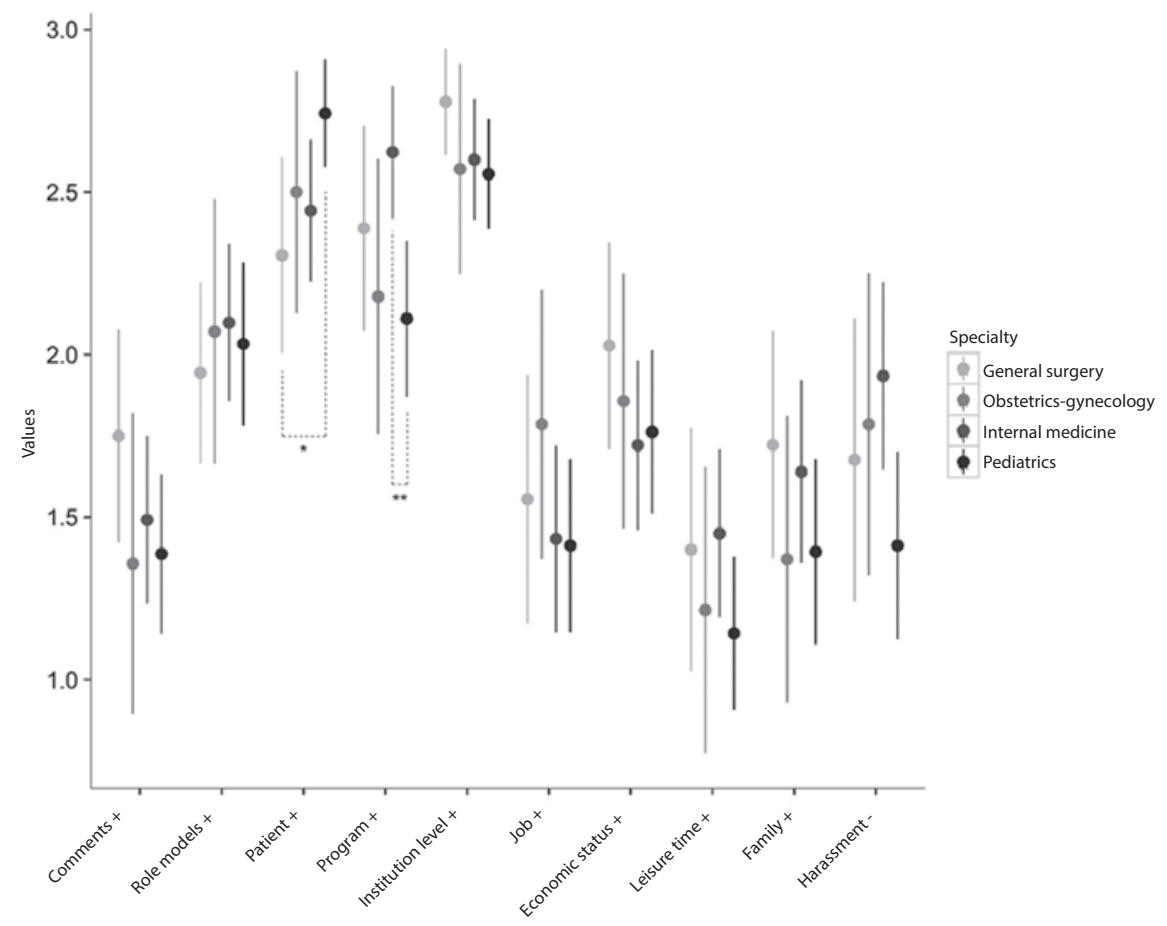

Figure 1. Answers for the factors related to the choice of the four studied specialties (the one that was the most interesting at the moment of choice). The means (dots) for the four specialties are shown. The post hoc analysis showed statistically significant differences $\left({ }^{*} p<0\right.$ '.05) between general surgery and pediatrics for the type of patient, and between internal medicine and pediatrics for an interesting academic program.

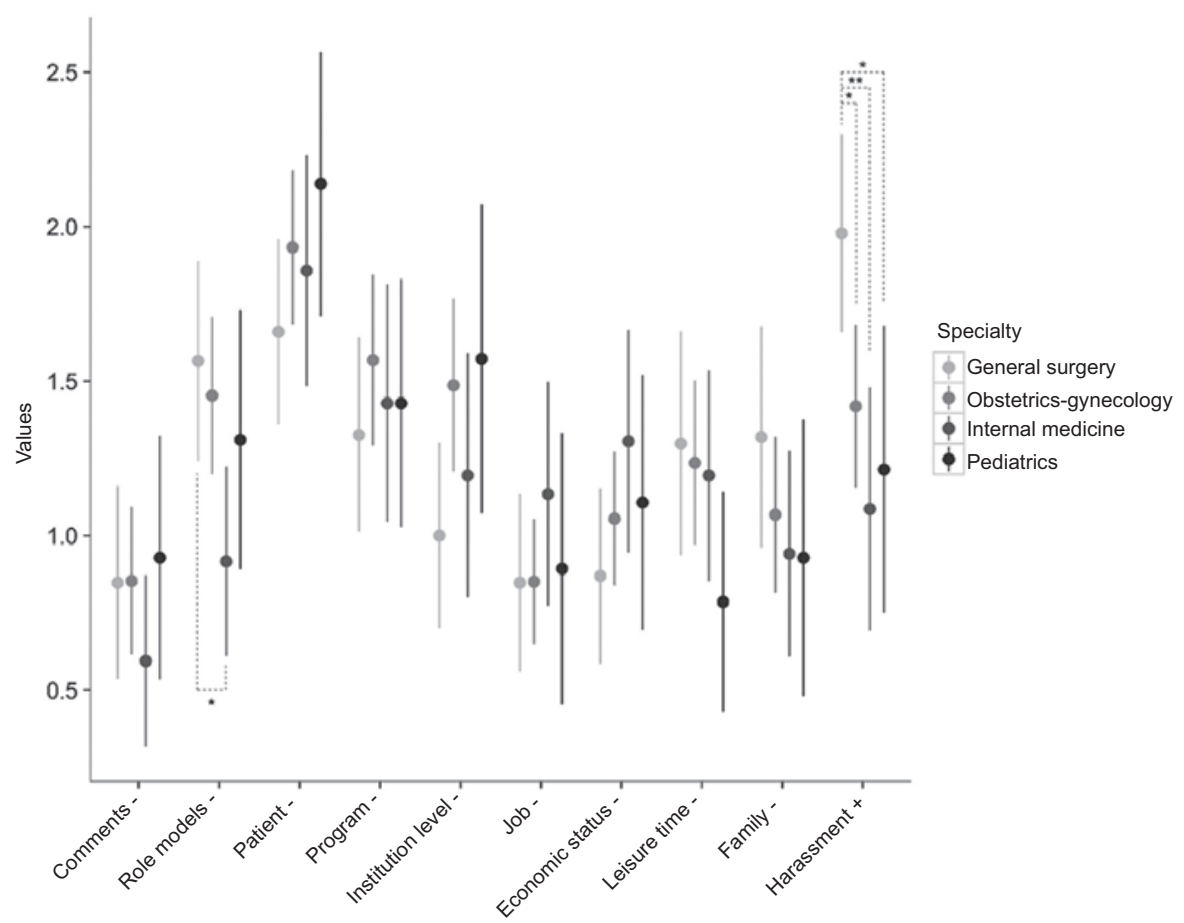

Figure 2. Answers for factors related to ruling out one of the studied specialties (the one that was the most interesting at the moment of choice). The means (dots) for the four specialties are shown. The post hoc analysis showed a statistically significant difference ( ${ }^{*} p<0$ '.05) between general surgery and internal medicine for negative role models, and between general surgery and the other three for the presence of harassment. A trend towards low academic level of the institution and having little leisure time can be noted.

openness, and 0.70 or higher for extraversion, emotional stability and responsibility. There were significant differences between the four specialties $(p<0.02)$ for extraversion and for responsibility. The 


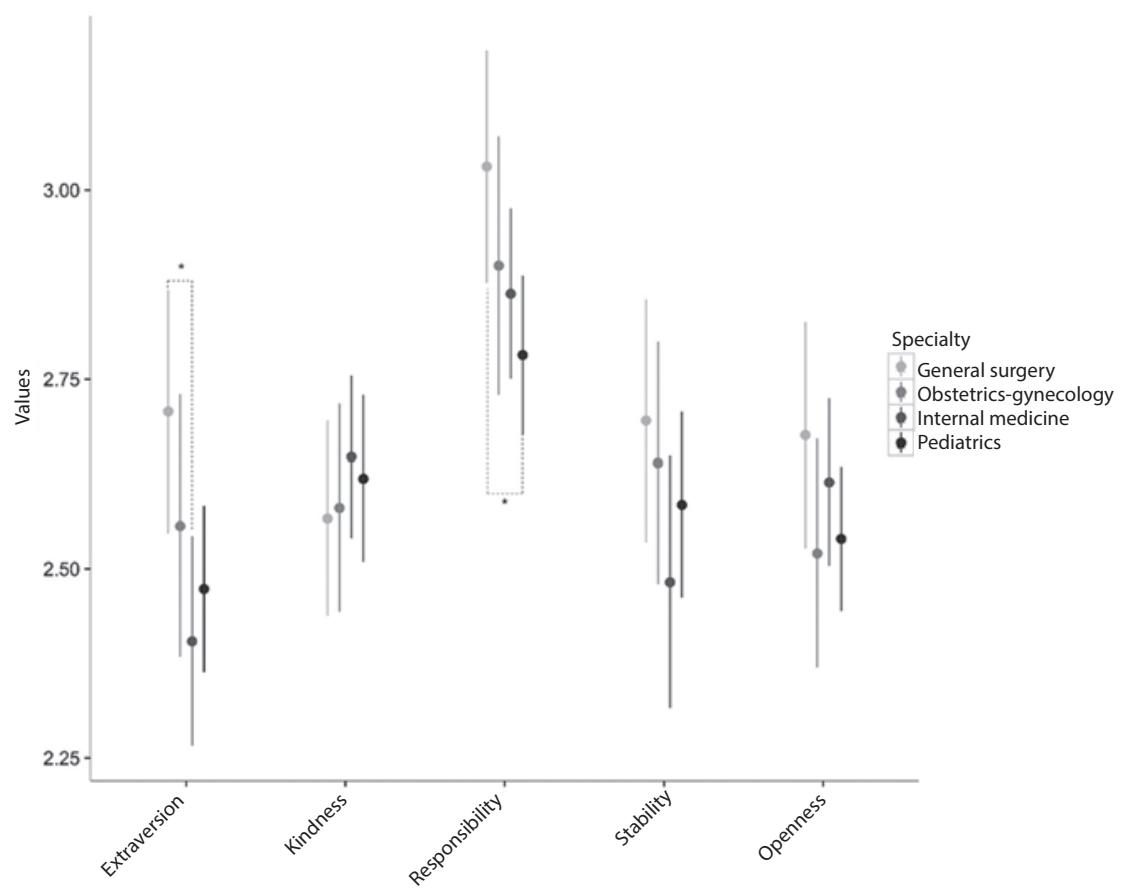

Figure 3. Personality normative questionnaire answers. The means (dots) and 95\% confidence intervals (lines) by personality traits are shown for all four specialties. The post hoc analysis showed a statistically significant difference $\left({ }^{*} p<0\right.$ '.05) between general surgery and internal medicine for the extraversion trait, and between general surgery and pediatrics for the responsibility trait.

analysis with Tukey's test showed that differences occur between general surgery (mean of 2.71) and internal medicine (mean of 2.4) for extraversion, and for general surgery (mean of 3.01 ) and pediatrics (mean of 2.79) with the responsibility trait. There were no significant differences for kindness, emotional stability and openness between the four studied specialties (Fig. 3). As regards the ipsative questionnaire, the low number of participants precluded having sufficiently stable results for analysis.

\section{Discussion}

In Mexico there is low offer of specialist physicians, with an inequitable distribution by States and an availability not corresponding to the epidemiological outlook of the country; in addition, the demand for medical residency posts largely exceeds the supply? This study provides information about different factors that explain why a first-year resident physician chooses one of the four core specialties.

Most surveyed physicians belong to the female gender, except for surgery, where, as in other countries, is a specialty where more males than females are enrolled ${ }^{22}$. Almost all were single and without children. Less than half the residents had relatives who were physicians, which appears not to be that determinant for the decision and differs from other reports ${ }^{23}$. In our investigation, most resident physicians chose their specialty during the clinical years or by the end of the undergraduate studies; exposure to medical or surgical experiences at the clinical stage can guide the decision towards a particular specialty. This is more common in male resident physicians: when they have more surgical rotations, they are more likely to choose surgery as specialty, as shown by the study by Coffeng ${ }^{24}$.

As observed in the study by Senf ${ }^{25}$, interest for the type of patient is highly important to choose a specialty. The doctor-patient relationship is determinant for the choice of family medicine; for internists, the fact of working with adults is important; and for pediatricians, working with children, and the doctor-patient relationship, as well as with other pediatricians, influences on the decision. This is in line with the present study: among the four specialties we evaluated, the type of patient was more important to choose pediatrics than for surgery, which is also described, since the aspects that influence on surgeons are other, such as already having made the decision before joining the undergraduate degree studies, practical intervention, manual activities and the therapeutic result obtained ${ }^{26,27}$. With regard to the curriculum, internists in this research chose more the specialty than pediatricians 
and obstetricians-gynecologists. The curriculum or study plan is not reported in other investigations. It draws the attention that this factor was not mentioned as important for the decision in the works performed with focus groups, and it will be therefore important investigating how the quality of academic programs influences on the choice of specialties.

Role models, just as teachers, are important because their acts and attitudes are observed by trainee physicians and, conscientiously or unconscientiously, they can influence on the medical practice the student decides to carry out in the future ${ }^{28}$. In this study, negative role models were more determinant for surgery to be ruled out as related to internal medicine. Role models, either positive or negative, influence on the choice of a surgical specialty, either for personality and manual skills, or for the ability to teach ${ }^{29,30}$.

Low academic level at the training institution was more determinant for not choosing pediatrics than for ruling out surgery, which was also a testimonial mentioned in the focus groups; the training hospital is an important factor for selecting in Mexican resident physicians, but neither is it mentioned as an important factor in other research works.

The presence of abuse was determinant for not choosing surgery, rather than to rule out internal medicine or pediatrics. This can be explained because the practice of harassment continues in surgical specialties, and is a factor that can be related to a woman deciding not to study surgery, although this factor tends to decrease owing to medicine feminization since the decade of $1980^{31,32}$. Harassment is experienced, observed or heard of during physicians' training. Other studies have identified this factor as a reason to rule out surgery (more often in females) and to rule out obstetrics-gynecology (more often in males $)^{31,32}$. In this study, with a population mostly comprised by females, women were found to rule out surgery owing to the presence of harassment, and this factor was less important for internists and pediatricians, which in turn consider other elements to be more determinant for their training, such as the type of patient, the curriculum and the training institution.

In this investigation, extraversion was the most characteristic personality trait of surgeons and the least common among internists. Surgeons are more extraverted than other specialists, and personality traits are more evident when surgeons are already in the specialty and not during medicine undergraduate program $^{10}$. For the other specialties, a certain homogeneity has been described to exist as regards personality according to the 5 big traits mode $\left.\right|^{9,10}$, and this can be explained because the population of resident physicians is quite alike once it starts its training, and the surveyed population corresponded to firstyear resident physicians. The variety of personality traits occurs more within a specialty rather than between medical specialties, which was consistent with the results obtained in our research, except for surgeons.

One of the limitations of the study was the qualitative information (focus groups), since the groups took place at three high specialty hospitals in Mexico City, where the training hospital is determinant to the choice, although the most information possible was tried to be obtained in the interview guide in order for it to be included in the questionnaire. With regard to the quantitative phase, the rate of answered questionnaires was $20 \%$, but the information was obtained from 133 secondary and tertiary care hospitals from 18 States. Although the survey could be answered in less than 20 minutes, the population of first-year core specialties resident physicians in Mexico has little time to answer surveys due to the high academic and work load. In addition, in health institutions, participation in each hospital's own works is privileged. As future investigation lines, it might be interesting including other specialties with lower rates, such as psychiatry (1.1), geriatrics (0.8) and others with high demand in Mexico, according to the epidemiological outlook of a country with an emerging economy.

It is important to consider that, in this study, multiple factors related to the choice of a specialty are assessed, which is highly important because most national or foreign studies assess only a few factors. One of the strengths of the study is that a qualitative phase and a quantitative phase are included in the methodology. The questionnaire, albeit long, can be rapidly answered. Finally, this research was carried out in resident physicians, and the way different factors determined the decision was assessed.

The future of medical specialties in Mexico is under study, and there are projections for the year 2030 aiming to improve the access, training and equity in the distribution of trainee specialist physicians ${ }^{33}$. In this investigative work, some factors that determine the decision of first year resident physicians were studied, such as the type of patient, the academic program, role models, characteristics of the training site and harassment. Research on how the above-mentioned elements influence, in addition to academic programs and other factors such as personality, will 
be important for having more elements that will contribute to a better choice of a specialty and in the selection and training of specialist physicians in the country.

\section{Acknowledgements}

To Margarita Varela MA and Tania Vives MA for their support in the qualitative phase, both for the focal groups and data analysis.

\section{References}

1. Bland $C$, Meurer L, Maldonado G. Determinants of primary care specialty choice: a non-statistical meta-analysis of the literature. Acad Med. 1995;70:620-41.

2. Bennett L, Phillips J. Finding, recruiting, and sustaining the future primary care physician workforce: a new theoretical model of specialty choice process. Acad Med. 2010;85:S81-8.

3. Querido S, Vergouw D, Wigersma L, et al. Dynamics of career choice among students in undergraduate medical courses. A BEME systematic review: BEME Guide No. 33. Med Teach. 2016;38:18-29.

4. Wijnen-Meijer M, Burdick W, Alofs $L$, et al. Stages and transitions in medical education around the world: clarifying structures and terminology. Med Teach. 2013;35:301-7.

5. Cantala D, Pereyra JS. El mercado de residencias médicas en México. Perspectivas. 2014;8:85-102.

6. Tirado J. Médicos desdeñan residencias en especialidades necesarias. Milenio (cultura) 8/9/2014. (Consultado el 15/5/2015.) Disponible en: http://www.milenio.com/cultura/Medicos-desdenan-residencias-especialidades-necesarias_0_368963118.html

7. Fajardo Dolci G, Santacruz Varela J, Lavalle Montalvo C. La formación de médicos especialistas en México. Documento de postura. México: Academia Nacional de Medicina; 2016.

8. OECD. Health at a glance 2015: OECD indicators. Paris: OECD Publishing; 2015. Disponible en: http://dx.doi.org/10.1787/health_glance-2015en

9. Seibert SE, Kraimer LM. The five-factor model of personality and career succes. J Voc Behav. 2001;58:1-21.

10. Borges JN, Savickas LM. Personality and medical specialty choice: a literature review and integration. J Career Ass. 2002;10:362-80.

11. Fetters MD, Curry LA, Creswell JW. Achieving integration in mixed methods designs - principles and practices. Health Res Educ Trust. 2013;48:2134-56.

12. Schifferdecker KE, Reed VA. Using mixed methods research in medical education: basic guidelines for researchers. Med Ed. 2009;43:637-44.

13. Senf $J H$, Kutob R, Campos-Outcalt D. Which primary care specialty? factors that relate to a choice of family medicine, internal medicine, combined internal medicine-pediatrics, or pediatrics. Med Stud Ed. 2004;36:123-30.
14. Hauer KE, Durning SJ, Kernan WN, et al. Factors associated with medical students' career choices regarding internal medicine. JAMA. 2008;300:1154-64.

15. Gaucher S, Thabut $D$. L'enseignement et l'ensegnant influencent le choix de la spécialité médicale. Enquête auprès de 207 étudiants. Presse Med. 2012;42:89-95.

16. Lima de Souza LG, Mendonça VR, García BC, et al. Medical specialty choice and related factors of Brazilian medical students and recent doctors. Plos One. 2015;137:1-15.

17. Artino AR, La Rochelle JS, Dezee KJ, et al. Developing questionnaires for educational research: AMEE Guide No. 87. Med Teach. 2014;36:463-74.

18. Brown A, Maydeu-Olivares A. Item response modeling of forced-choice questionnaires. Ed Psych Mes. 2011;71:460-502.

19. Hontagas PM, Leenen I, De la Torre J, et al. Traditional scores versus IRT estimates on forced-choice tests based on a dominance model. Psicothema. 2016;28:76-82.

20. Costa PT Jr, McCrae RR. Revised NEO Personality Inventory (NEO$\mathrm{PI}-\mathrm{R}$ ) and NEO Five-Factor Inventory (NEO-FFI) manual. Odessa, 1992. Psychological Assessment Resources.

21. Maples JL, Guan L, Carter NT, et al. A test of the International Personality Item Pool representation of the Revised NEO Personality Inventory and development of a 120-item IPIP-based measure of the five-factor model. Psych Assess. 2014;26:1070-84.

22. McLemore CE, Ramamoorthy S, Peterson YC, et al. Women in surgery: bright, sharp, brave, and temperate. Perm J. 2012;16:54-9.

23. Lima de Souza LC, Mendonça VR, Garcia CGB, et al. Medical specialty choice and related factors of Brazilian medical students and recent doctors. Plos One. 2015;10:1-15.

24. Coffeng LE, Visscher AJE, Ten Cate OTHJ. The influence of early clinical experiences on career preference of male and female medical students. Med Teach. 2009;31:e323-6.

25. Senf HJ, Kutob R, Campos-Outcalt $D$. Which primary care specialty? Factors that relate to a choice of family medicine, internal medicine, combined internal medicine-pediatrics, or pediatrics. Med Stud Ed. 2004;36:123-30

26. Bellodi PL. Surgery or general medicine - a study of the reasons underlying the choice of medical specialty. Sao Paulo Med J. 2004;122:81-6.

27. Hochberg MS, Billig J, Berman RS, et al. When surgeons decide to become surgeons: new opportunities for surgical education. Am J Surg. 2014;207:194-200.

28. Healy NA, Cantillon $P$, Malone $C$, et al. Role models and mentors in surgery. Am J Surg. 2012;204:256-61.

29. Glynn RW, Kerin MJ. Factors influencing medical students and junior doctors in choosing a career in surgery. Surgery. 2010;8:187-91.

30. Cochran A, Melby S, Neumayer LA. An internet-based survey of factors influencing medical student selection of a general surgery career. Am J Surg. 2005;189:742-6.

31. Stratton TD, McLaughlin AM, Witte MF, et al. Does students' exposure to gender discrimination and sexual harassment in medical school affect specialty choice and residency program selection? Acad Med. 2005;80:400-8.

32. Cook AF, Arora VM, Rasinski AK, et al. The prevalence of medical student mistreatment and its association with burnout. Acad Med. 2014;89:749-54.

33. Ruelas Barajas E, Alonso Concheiro A. Futuros de las especialidades médicas en México. Documento de postura. México: Academia Nacional de Medicina; 2015. 


\section{Appendix}

Appendix 1. Focal groups interview guide

1. Which factors did you take into account when you chose your specialty?

2. Would you remember well those factors? Did you consider them to be determinant?

3. When did you make said decision: at undergraduate program admission, at internship, at social service, at last moment?

4. Which persons influenced the decision making? Friends, parents, physician relatives, teachers?

5. Which personality components do you think would be important for selecting a specialty?

6. Did the lifestyle characteristics of a specialty influence on your motivation to choose it?

7. How important do you think the curriculum was to choose the specialty?

8. And the training hospital, was important when making the decision?

9. What influence had harassment (bullying) by your superiors or your peers on the choice?

10. If you would change your decision during the specialty training, which factors do you believe would be determinant for it?

11. What information is missing or biased to make a clear and convinced decision about the specialty? Do you have any example?

12. If you would have not chosen that specialty, which other would you have studied? Why?

13. What else do you suggest should be asked in a questionnaire that evaluates the factors that influence on the choice of a specialty? 